\title{
Whether and Where to Give ${ }^{1}$ \\ (Forthcoming in Philosophy and Public Affairs)
}

\author{
Theron Pummer \\ University of St Andrews
}

\section{The Ethics of Giving and Effective Altruism}

The ethics of giving has traditionally focused on whether, and how much, to give to charities helping people in extreme poverty. ${ }^{2}$ In more recent years, the discussion has increasingly focused on where to give, spurred by an appreciation of the substantial differences in costeffectiveness between charities. According to a commonly cited example, $\$ 40,000$ can be used either to help 1 blind person by training a seeing-eye dog in the United States or to help 2,000 blind people by providing surgeries reversing the effects of trachoma in Africa. ${ }^{3}$ Effective altruists recommend that we give large sums to charity, but by far their more central message is that we give effectively, i.e., to whatever charities would do the most good per dollar donated. ${ }^{4}$ In this paper, I'll assume that it's not wrong not to give bigger, but will explore to what extent it may well nonetheless be wrong not to give better.

The main claim I'll argue for here is that in many cases it would be wrong of you to give a sum of money to charities that do less good than others you could have given to instead, even if

\footnotetext{
${ }^{1}$ I am extremely grateful to Derek Parfit, Roger Crisp, Jeff McMahan, and Peter Singer for extremely helpful feedback and encouragement. I am also very grateful to Johann Frick, Ulla Wessels, William MacAskill, Richard Arneson, Brian McElwee, Hilary Greaves, Elizabeth Ashford, Justin Snedegar, Ben Sachs, Sarah Broadie, Andreas Mogensen, Gulzaar Barn, Iason Gabriel, Carissa Véliz, Larry Temkin, Toby Ord, Teru Thomas, Owen Schaefer, Michelle Hutchinson, Caleb Ontiveros, Jesse Tomalty, Tom Ash, Kevin Wong, Caley Anderson, Tim Campbell, Farbod Akhlaghi-Ghaffarokh, Paul Woodruff, Ben Lange, Tina Rulli, Luc Bovens, Thomas Pogge, Francesca Minerva, Alberto Giubilini, Seth Lazar, Christian Barry, Felix Pinkert, Julian Savulescu, and the editors and two anonymous readers at Philosophy and Public Affairs for very helpful comments. I would also like to thank audiences at the University of Melbourne, Charles Sturt University, The Australian National University, two audiences at University of St Andrews, and three audiences at University of Oxford. Special thanks go to Frog Asia and my Oxford summer school students in Philosophy, Politics, and Economics at the Garden International School, Kuala Lumpur, Malaysia for tolerating endless thought-experiment polling using "clickers," and to Oscar Westerblad for writing a nice piece titled "Giving what we can: St Andrews lecturer changes the way we think about charity" for The Saint (the St Andrews student newspaper), summarizing a public lecture based on this paper that I gave for the St Andrews Philosophy Society. Finally, I am pleased to note that this paper developed from a post I wrote for Oxford's Practical Ethics blog in December 2014.

${ }^{2}$ Peter Singer, "Famine, Affluence, and Morality," Philosophy and Public Affairs 1 (1972): 229-43; Liam Murphy, "The Demands of Beneficence," Philosophy and Public Affairs 22 (1993): 267-92; Peter Unger, Living High and Letting Die: Our Illusion of Innocence (New York: Oxford University Press, 1996); and Garrett Cullity, The Moral Demands of Affluence (Oxford: Clarendon Press, 2004).

${ }^{3}$ Toby Ord, "The moral imperative towards cost-effectiveness in global health," Washington, D.C.: The Centre for Global Development, 2013: www.cgdev.org/content/publications/detail/1427016.

${ }^{4}$ Peter Singer, The Most Good You Can Do: How Effective Altruism Is Changing Ideas About Living Ethically (London: Yale University Press, 2015); William MacAskill, Doing Good Better: Effective Altruism and A Radical New Way to Make a Difference (London: Faber \& Faber Ltd., 2015); Iason Gabriel, "Effective Altruism and Its Critics," Journal of Applied Philosophy (2016) doi:10.1111/japp.12176; and Jeff McMahan, "Philosophical Critiques of Effective Altruism," forthcoming in The Philosophers' Magazine.
} 
it would not have been wrong of you not to give the money to any charity at all. I'll assume that all the charities under discussion here do positive good overall, do not cause harm, do not infringe rights, etc. ${ }^{5}$

What makes my main claim here particularly interesting is that it is inconsistent with what appears to be a fairly common assumption in the ethics of giving, according to which if it is not wrong of you to keep some sum money for yourself, then it is likewise not wrong of you to donate it to any particular charity you choose. ${ }^{6}$ Roughly: if it's up to you whether to donate the money, it's also up to you where to donate the money. I will challenge this common assumption.

\section{Moral Options}

I'll here conceive of "good" and "bad" from an impartial, or agent-neutral, perspective. Suppose that in one outcome, you consume an ice cream cone, and, for some unrelated reason and unbeknownst to you, five distant people suffer intense pain and die. In a second outcome, none of these things occur. While the first outcome may be better for you than the second, the first outcome seems worse than the second from an impartial perspective. ${ }^{7}$ Or, as I'll more simply say, the first outcome seems worse. I'll occasionally refer to acts as better or worse; this is merely an economical way of referring to acts that promote better or worse outcomes. (Also, throughout the paper "good" can be replaced with "expected good," and "outcomes" can be replaced with "prospects," etc., without any loss to the main argument.)

According to consequentialism, an act is wrong if and only if and because it promotes a worse outcome than another available act would have done. My argument against the common assumption will be non-consequentialist in nature. That is, while I will suppose that promoting the good is a morally relevant factor, I will suppose that it is not the only morally relevant factor. In particular, I will suppose that there are moral options, according to which it is at least sometimes not wrong for you to act in a way that would result in less good than if you had performed some other act instead. ${ }^{8}$ It may well be best, for example, for you to give away nearly all of your income to a cost-effective charity while working tirelessly to earn still more to give. If so, then both consequentialism and "consequentialism-plus-constraints" "would imply that it

\footnotetext{
${ }^{5}$ For discussions about the risks of doing harm in giving to overseas aid agencies, see Leif Wenar, "Poverty is No Pond: Challenges for the Affluent," in Giving Well: The Ethics of Philanthropy, eds. Patricia Illingworth, Thomas Pogge, and Leif Wenar (Oxford: Oxford University Press, 2010), pp.104-32; Christian Barry and Gerhard Øverland, Responding to Global Poverty: Harm, Responsibility, and Agency (Cambridge: Cambridge University Press, 2016); and my "Risky Giving," forthcoming in The Philosophers' Magazine.

${ }^{6}$ I would estimate that about half the people I have raised this with have found the common assumption to be plausible (I have raised this with at least 300 people, including philosophers and non-philosophers).

${ }^{7}$ Not everyone believes there is such a thing as "better than, period" (see Judith Jarvis Thomson, Normativity (Chicago and La Salle, Illinois: Open Court, 2008), and see Richard Arneson, "Good, Period," Analysis 70: 731-44 for a reply). While I believe there is, it seems to me that the main task the notion of "better than, period" is put to in this paper could be performed just as well by some other notion (e.g., what's preferred from the standpoint of impartial benevolence).

${ }^{8}$ See Samuel Scheffler, The Rejection of Consequentialism (New York: Oxford University Press, 1982) and Shelly Kagan, The Limits of Morality (Oxford: Clarendon Press, 1989).

${ }^{9}$ According to this view, it is wrong not to promote the most good, as long as promoting the most good does not involve the violation of any deontological constraint (such as the constraint against causing harm).
} 
would be wrong of you not to do so. But, with intuition and commonsense morality, I will suppose that it is not wrong of you not to make such substantial sacrifices of your own wellbeing, i.e., you possess the moral option not to do so.

Merely to keep my discussion relatively tidy, I'll be assuming that the primary agentneutral reasons for donating to charity are rooted in promoting the good, or benevolence, rather than in justice, e.g., respecting human rights or discharging duties of compensation or rectification. ${ }^{10}$

\section{Optionality about Whether to Help}

So there are moral options. But what is the basis of the moral option not to help others, e.g., by giving to charity, when doing so would be best? A very natural and plausible answer is that the basis of such a moral option is the cost to you, the agent. If in order to rescue a drowning child you had to sacrifice both your legs, then intuitively you would have the moral option not to help. But if the only cost to you of saving the drowning child were muddied shoes, you would lack the moral option not to help. In both scenarios, we can assume that it would be best to help. What makes it not wrong not to do what's best in the first scenario is the substantial cost to you; since the cost to you in the second scenario is very small, no such moral option is triggered, and so here it is wrong not to do what's best.

The basis of the moral option not to do what's best is plausibly somewhat more complex - a function both of the amount of good you would do if you did what's best, as well as the cost to you of doing so. Nonetheless, for convenience I will in the first instance focus just on the cost to you.

Moreover, and importantly, I'll here construe "cost" very broadly to include any loss to you in terms of your well-being, desires, projects, personal concerns, special relationships, etc. ${ }^{11}$ Arguably these various sorts of cost are distinct and can come apart, e.g., arguably you can sacrifice your well-being in order to promote your projects. For present purposes I will remain agnostic about whether this is correct. The reason I construe "cost" so broadly is to be inclusive about what the basis of the moral option not to do what's best might be. At least, everything I argue here is consistent with taking losses to you in terms of your well-being, projects, or

\footnotetext{
${ }^{10}$ On justice, see Thomas Pogge, World Poverty and Human Rights: Cosmopolitan Responsibilities and Reforms (Cambridge: Polity Press, 2002) and Elizabeth Ashford, "Severe Poverty as an Unjust Emergency," forthcoming in Paul Woodruff, ed., Philanthropy and Philosophy: Putting Theory Into Practice (New York: Oxford University Press).

${ }^{11}$ If "cost" is construed broadly enough to include losses in terms of your desires, one might worry that you doing anything other than what you actually do would involve some cost to you. After all, perhaps necessarily whenever you voluntarily do A rather than B, you desire A rather than B. There are two responses to this worry. First, we could construe "desires" in a narrow enough way that leaves room for the possibility of voluntarily doing A rather than B whilst not desiring A rather than B. Second, we could allow that you doing anything other than what you actually do would involve some cost to you, but deny that such costs could generate any significant moral options (also see the discussion of "bare moral freedom" below).

The notion of "cost" might be broadened further still, e.g., to incorporate difficulty (see Brian McElwee, "What is Demandingness?" forthcoming in The Limits of Moral Obligation, eds. Marcel van Ackeren and Michael Kühler (New York: Routledge)), or to incorporate various brute agent-relative considerations (one might argue that the fact that my friend was killed by a drunk driver itself gives me a reason to campaign against drunk driving, independently of whether such campaigning would further my desires, personal concerns, or special relationships).
} 
personal concerns, etc. as the basis of such a moral option. It is also consistent with the view that it's the cost to you over the course of your whole life, rather than merely the cost to you now, that serves as the basis of the moral option. The cost to you on some particular occasion might be small, but it may not be wrong of you to refuse to incur it if in the past you've incurred substantial costs for the sake of promoting the good. But again this paper is not about how much one must give to charity to avoid acting wrongly. I will not be defending any answer to the question of how big the cost to you needs to be for it to be the case that it would not be wrong for you not to give, even when giving would be best. ${ }^{12}$

There are many cases in which you can either do nothing or instead perform one of a number of helpful acts, where each of the helpful acts would do more good than doing nothing, but the cost to you of doing any of the helpful acts is high enough that it would not be wrong of you to do nothing (as with charities, I'll assume that none of the helpful acts in question cause harm, infringe rights, etc.). In such cases, I'll say that there's optionality about whether to help. In this section I've claimed that the basis of such optionality is the cost to you.

\section{Optionality about Where to Help}

What about optionality about where to help, i.e., having the moral option to perform some helpful acts over others, even when they would do less good? The same basis of the moral option not to help at all sometimes also serves as the basis of the moral option to perform some helpful acts over others. Suppose there are two charities: giving your $\$ 1,000$ to one would do slightly less good than giving it to the other, but the first charity represents a cause much closer to your heart, e.g., fighting blindness. Arguably, it'd not be wrong of you to give your $\$ 1,000$ to the first charity, even though this is not best. This is because the cost to you of giving to the other charity instead of this one is substantial. Thus, we should not unqualifiedly claim that while it is permissible not to give a large portion of your income to charity, it would be wrong not to allocate whatever portion you do give in whatever way would do the most good. The basis of the moral option not to give will sometimes also serve as the basis of the moral option where to give. ${ }^{13}$

Nonetheless, my main claim here is that in many cases it would be wrong of you to give a sum of money to charities that do less good than other charities you could give to instead, even if it would not have been wrong of you not to give the money to any charity at all. This claim is inconsistent with the common assumption noted above that if it is not wrong of you to keep some sum of money for yourself, then it is likewise not wrong of you to donate it to any particular charity you choose. Unless there is something morally special about money, this particular common assumption goes hand-in-hand with the more general

\footnotetext{
${ }^{12}$ See footnote 1. In "Giving Isn't Demanding," forthcoming in Paul Woodruff, ed., Philanthropy and Philosophy: Putting Theory Into Practice (New York: Oxford University Press), Andreas Mogensen, William MacAskill, and Toby Ord argue that giving money to charity doesn't typically involve a sacrifice of as much well-being as we tend to assume it does.

${ }^{13}$ Thus I agree with Hilary Greaves ("Cancer Care and Saving Parrots," keynote lecture given at The Philosophical Foundations of Effective Altruism conference at the University of St Andrews, March 30, 2016) that it would be a mistake for effective altruists to claim that there is a sharp asymmetry between how mисh and where to give, according to which while one is not required to give whatever amount would be best, one is required to give to the best charities only (if one does give).
} 
Common Assumption: Optionality about whether to help at all entails optionality about which particular helpful act to perform.

Therefore, arguing against Common Assumption constitutes an important initial phase of my defense of my main claim.

\section{Optionality Whether to Help Without Optionality Where to Help}

In arguing against Common Assumption, I'll appeal to a case involving some speedy runaway trains.

Arm Donor: There is one innocent stranger stuck on track A, and a runaway train headed straight toward her. There are one hundred innocent strangers stuck on track B, and another runaway train headed straight toward them. If you do nothing, all one hundred and one people will soon die. However, you can use your arm as a train-stopper; those tied to the tracks are far enough away that putting your arm on either track would cause the relevant train to slow down and come to a complete stop before reaching anyone in its path. That is, if you place your arm on track A, you'll stop the train on that track in time and save the one, and, if you place your arm on track B, you'll stop the train on that track in time and save the hundred. You have no other means of saving any of these people. Since the two tracks are 20 feet apart, you won't be able to sacrifice more than one arm in time to save all one hundred and one. Assume that losing your arm is a large enough cost to you to make it not wrong not to incur this cost, whether that's in order to save one life or one hundred. All other things are equal.

While not wrong to do nothing, and not wrong to place your arm on track B, saving the hundred, it seems it would be wrong for you to place your arm on track A, saving the one. ${ }^{14}$ In general, it seems wrong to fail to save more lives when this is no costlier to you, other things

\footnotetext{
${ }^{14}$ Derek Parfit ("Future Generations: Further Problems," Philosophy and Public Affairs 11 (1982): 113-172, p.131, and On What Matters, Volume Two (Oxford: Oxford University Press, 2011), p.225) and Shelly Kagan (The Limits of Morality, p.16) make similar claims about similar cases. However, neither has addressed the range of issues and objections such claims give rise to, and neither has applied the lessons learned to the context of charitable giving (both of which I hope this paper will at least begin to do). Moreover, their cases do not always match the structure of the case of giving to charity. For example, in Kagan's case, at an earlier time you have the choice of whether to incur a large cost (by running into a burning building), and if you do, then at a later time you have the choice of where to help (to rescue a child or a parrot, where there's no further cost to you of rescuing one over the other). But in the case of giving to charity you have the choice of whether to incur a large cost and the choice of where to help available at the same time, i.e., at a given time you can donate nothing, donate to charity A, donate to charity B, donate to charity $\mathrm{C}$, or... etc. Even if you take a public pledge to give $10 \%$ of your income wherever you believe it will do the most good (as members of the organization Giving What We Can do), you have not yet irrevocably given this money to charity, whereas in Kagan's case once you run inside the building you've already paid the relevant cost. Unless you bind your future self in some more reliable way, after taking the pledge you'll still have the choice of whether to give at all as well as where to give.
} 
equal. If these intuitions are correct, then, contrary to Common Assumption, we have optionality about whether to help without optionality about where to help.

If you think it makes for a clearer or otherwise better example, you can restate the case so that the cost to you of stopping either train is substantial pain or some other kind of serious wellbeing setback, rather than the loss of a limb. Moreover, if you are skeptical that it is wrong not to save the greater number (even when other things are equal), ${ }^{15}$ you can substitute different specific details such that stopping the train on track A promotes 1 unit of good whereas stopping the train on track B promotes 100 units of good. The point I'm arguing for here is not wedded to any terribly specific account of what the good consists in, or to the claim that the number of lives saved matters, etc. But for the sake of concreteness it often helps to work in terms of different numbers of lives saved. General-level intuition here appears to support the following principle:

Avoid Gratuitous Worseness (weak): It is wrong to perform an act that is much worse than another, if it is no costlier to you to perform the better act, and if all other things are equal.

Two remarks about this principle: First, it is somewhat stronger than the intuitive claims made about Arm Donor. Though controversial, let us suppose for the sake of illustration that it would be much better to bring into existence many people who would have lives well worth living than to refrain from doing so. Even if so, we might think it would not be wrong of you to refrain from doing this, even if it were no costlier to you to do so than not. ${ }^{16}$ While we might thereby deny Avoid Gratuitous Worseness (weak), it seems the principle could be weakened to accommodate such thoughts. For instance, we could instead restrict the principle to acts that are much worse than others in virtue of failing to significantly benefit existing people who are not very well off, or in virtue of failing to spare such people from significant harm. Since adopting this restricted version of Avoid Gratuitous Worseness (weak) would create no special obstacles for my argument for my main claim here, I will, for ease of presentation, refer to the original, unrestricted version. Readers should feel free to interpret "worseness" here along the lines of failure to significantly benefit existing people etc.

Second, Avoid Gratuitous Worseness (weak) is compatible with the view that, in many cases, there is no best act. Instead there may be only an "upper set" of acts, such that any act in this upper set is better than any act outside it, and such that those acts within the upper set are roughly equally good, on a par, or incommensurable ${ }^{17}$ - or perhaps it is indeterminate how acts in the upper set rank in comparison to one another, or maybe we are just utterly clueless as to how they do. Arguably such cases are especially likely to arise in the context of giving to

\footnotetext{
${ }^{15}$ For example, see John Taurek, "Should the Numbers Count?" Philosophy and Public Affairs 6 (1977): 293-316; Derek Parfit, "Innumerate Ethics," Philosophy and Public Affairs 7 (1978): 285-301; Frances Kamm, Morality, Mortality, Volume I: Death and Whom to Save from It (New York: Oxford University Press, 1993); Jens Timmermann, "The Individualist Lottery: How People Count, but Not Their Numbers," Analysis 64 (2004): 106-12; S. Matthew Liao, "Who Is Afraid of Numbers?" Utilitas 20 (2008): 447-461; and Kieran Setiya, "Love and the Value of a Life," Philosophical Review 123 (2014): 251-280.

${ }^{16}$ For example, see Michael Tooley, "Value, obligation and the asymmetry question," Bioethics 12 (1998):111-124.

${ }^{17}$ For a useful introduction to these and related notions see Ruth Chang, "The Possibility of Parity," Ethics 112 (2002): 659-88 and "Value Incomparability and Incommensurability," in eds., Iwao Hirose and Jonas Olson, Oxford Handbook of Value Theory (Oxford: Oxford University Press, 2014).
} 
charity, as many charitable causes are difficult to compare. Thus there may be no best charity, but only an upper set of charities. ${ }^{18}$

Recall that in Arm Donor, you have three acts available to you at a single time:

(i) Do nothing

(ii) Do a helpful act

(iii) Do a much more helpful act

where (i) involves no cost to you; (ii) would promote more good than (i); (iii) would promote much more good than (ii); the cost to you of doing either (ii) or (iii) is substantial; the cost to you of doing either (ii) or (iii) is the same.

In the context of Arm Donor, I claimed that (i) and (iii) are not wrong, but that (ii) is wrong. This seems a plausible particular-level claim. But it is also supported by the plausible general principle, Avoid Gratuitous Worseness (weak). This principle implies that (ii) is wrong. The existence of moral options implies that (i) is not wrong. And (iii) is clearly not wrong. So we have particular-level and general-level intuitive support for this moral ranking of (i), (ii), and (iii). Since Common Assumption implies that (ii) is wrong only if (i) is too, we have intuitive support in favor of its denial. ${ }^{19}$

One might skeptically respond: "How can it be not wrong to stand by and do nothing but wrong to rather kindly incur a cost and do something better than doing nothing?" This question is intended to provoke the intuition that the moral ranking of (i), (ii), and (iii) I've offered is an implausible one, in virtue of assigning (i) a higher moral status than (ii). ${ }^{20}$ The intuition here is that (ii) is wrong only if (i) is wrong too. One might then continue: the implausibility of this moral ranking not only shows that Avoid Gratuitous Worseness (weak) has implausible implications, but that, on reflection, it is not an intuitively plausible principle after all.

I do not agree. True, if (i) and (ii) were the only available acts, it would be permissible to perform (ii). But it is a familiar feature in non-consequentialist ethics that the moral status of an act can depend on which alternative acts are available. In this case, the presence of (iii) alters the moral status of (ii), thereby altering the way that (ii) and (i) compare morally. I believe the intuition that (ii) is wrong only if (i) is wrong too has force only when considering these acts in isolation from the full choice situation. But with the full choice situation in view, it is clear that

\footnotetext{
${ }^{18}$ Here one might consult www.givewell.org and www.givingwhatwecan.org.

${ }^{19}$ We can usefully put the point in terms of conditional obligations. You are not under any unconditional obligation to do (ii) or (iii); that is, it is not wrong to do (i). However, you are under an obligation to do (iii), conditional on it being the case that you in fact do either (ii) or (iii). For work on conditional obligations, which further reinforces the particular picture I'm defending here, see Ulla Wessels, "Beyond the Call of Duty: The Structure of a Moral Region," Royal Institute of Philosophy Supplement 77 (2015): 87-104 and Tina Rulli, "Conditional Obligations” (unpublished). The three of us (Wessels, Rulli, and I) have converged on similar accounts independently of one another.

It is also worth noting that while Scheffler's agent-centered prerogative (The Rejection of Consequentialism) is consistent with the above moral ranking of (i), (ii), and (iii), it is far more demanding than Avoid Gratuitous Worseness (weak); Scheffler's view implies that no matter how costly it is for you to perform an act, you'd be morally required to perform it if doing so would promote enough good.

${ }^{20}$ Jeff McMahan raises this sort of concern in "Doing Good and Doing the Best," forthcoming in Paul Woodruff, ed., Philanthropy and Philosophy: Putting Theory Into Practice (New York: Oxford University Press); on p.5 of his manuscript, he writes, "...can we really believe that the only one who has done wrong is the only one who has done any good at all - and in conditions in which it was permissible for her not to do any?"
} 
there is something to be said against (ii) that cannot be said against (i) or (iii): the performance of (ii) constitutes a deliberate refusal to do something much better at no extra cost. This is a serious moral failing.

So there are some cases in which there is optionality about whether to help without optionality about where to help. Unless there's something particularly morally relevant about helping by giving away limbs to stop trains as opposed to helping by giving away money to fund charities, we should also accept that there are some cases in which there is optionality about whether to give without optionality about where to give.

Here one might respond that there is something morally special about money; in particular, one might argue that moral property rights can generate optionality about whether and where to give. But it seems dubious that moral property rights generate either sort of optionality when you can do a lot of good at no cost to yourself, or a lot more good at no extra cost to yourself. Suppose you have the moral property right to the $\$ 1,000$ in your legal possession, but that (perhaps because you enjoy helping others) it'd not be costly to you all-things-considered to give away this $\$ 1,000$ to save a life. Intuitively it would be wrong not to give away the money to save a life. Next we can suppose instead that it would be very costly to you to give away the $\$ 1,000$, such that it wouldn't be wrong not to give it away to save lives. Now, faced with the choice of using your $\$ 1,000$ to save one stranger or to save one hundred, and supposing it's equally costly to you to do either act, it seems implausible that it would be permissible to save the one merely on the basis of moral property rights. Appeals to moral property rights cannot plausibly support the general claim that if it's up to you whether to donate a sum of money, then it's also up to you where to donate the money. ${ }^{21}$

Finally, one might argue that you simply enjoy some degree of bare moral freedom that, independently of cost (in my broad sense) and independently of moral property rights, gives you the moral option to do less good than you could have done. There are good reasons to be skeptical of such bare moral freedom as an independent source of moral options. ${ }^{22}$ Even bracketing this skepticism, bare moral freedom seems insufficient to generate optionality about whether to give when you can do a lot of good at no cost to yourself, and insufficient to generate optionality about where to give when you can do a lot more good at no extra cost to yourself. This is for reasons parallel to those cited above in connection with moral property rights, e.g., even if it is permissible for you not to give away your $\$ 1,000$ to save lives, if faced with the choice of using your $\$ 1,000$ to save one stranger or to save one hundred, and if it were equally costly to you to do either act, it seems implausible that it would be permissible to save the one merely on the basis of bare moral freedom.

\footnotetext{
${ }^{21}$ It is controversial to what extent affluent people actually $d o$ possess moral property rights to the wealth legally in their possession. There are competing theories of just acquisitions and transfers of property, and on some of them it's dubious that the most affluent people in the world have moral property rights to all of the wealth legally in their possession. Arguably one is morally required to use whatever property one legally possesses but lacks moral property rights to in the impartially best way (or, at least, one's moral options concerning the use of such property are far less extensive than they'd otherwise be). These remarks are inspired by Jeff McMahan (personal communication), Elizabeth Ashford (“Severe Poverty as an Unjust Emergency”), and by Derek Parfit's 2015 address to the Oxford Union: https://www.youtube.com/watch?v=xTUrwO9-B_I.

${ }^{22}$ See Shelly Kagan (The Limits of Morality) and Richard Arneson, "Moral Limits on the Demands of Beneficence?" in The Ethics of Assistance: Morality, Affluence, and the Distant Needy, ed. by Deen K. Chatterjee (Cambridge: Cambridge University Press, 2004), pp.33-58.
} 


\section{Can We Cheaply Avoid Gratuitous Worseness?}

Consider once again the choice between:

(i) Do nothing (keep $\$ 1,000$ for yourself)

(ii) Do a helpful act (give $\$ 1,000$ to charity A)

(iii) Do a much more helpful act (give $\$ 1,000$ to charity B)

Again: (i) involves no cost to you; (ii) would promote more good than (i); (iii) would promote much more good than (ii); the cost to you of doing either (ii) or (iii) is substantial; the cost to you of doing either (ii) or (iii) is the same.

Suppose that, on the basis of the substantial cost to you, it is not wrong not to give the $\$ 1,000$ to charity. Given the particulars of the case, I've argued that (i) and (iii) are not wrong, whereas (ii) is wrong.

One might object: "Acceptance of your view will motivate readers to switch from less cost-effective giving (ii) to not giving at all (i). They will prefer to avoid wrongdoing the cheap way." 23

The first thing to note in response is that even if accepting my view would have undesirable effects, this is no objection to its truth. The second is that it is doubtful readers will in fact react to reading my paper by not giving at all, though this is an empirical claim I cannot defend here. A further point an effective altruist would urge us to consider: even if many readers did switch from (ii) to (i), as long as just a small proportion switched from (ii) to (iii) this would remain a net change for the better, given that the (iii) type charities in the "upper set" arguably do so much more good per dollar donated than those (ii) type charities outside it.

One might next object: "Your view permits a switch from less cost-effective giving (ii) to not giving at all (i), as after all on your view (i) is permissible. That is implausible."

There are two responses available here. Obviously I could resist, arguing that it permissible to switch from (ii) to (i). On the other hand, I could revise my view so that it avoids implying that it is permissible to switch from (ii) to (i). The objection cannot be to the permissibility of (i) when not switching from (ii) - this would be too broad, and at odds with the assumption that there is a moral option that permits the agent to do (i). Thus those pressing the objection must recognize some condition on the permissibility of (i) such that while (i) is wrong in all or at least some cases of switching from (ii), it is not wrong when not switching from (ii). I had been assuming up to this point in the paper that agents who would choose (i) were not switching from (ii). In these familiar non-switching cases the condition on the permissibility of (i) is satisfied, yielding the familiar moral ranking: (i) and (iii) are permissible, whereas (ii) is wrong. But in all or at least some switching cases the condition on the permissibility of (i) isn't satisfied, and so only (iii) is permissible.

I will not attempt here to determine whether the "resist" response or the "revise" response is more plausible. Those who find the former implausible should find the latter plausible, and those who find the latter implausible should find the former plausible. This is sufficient for my

\footnotetext{
${ }^{23}$ In a similar vein, Bernard Williams wrote of Singer's view (as first presented in "Famine, Affluence, and Morality") that, "As moral persuasion, this kind of tactic is likely to be counterproductive and to lead to a defensive and resentful contraction of concern" (Ethics and the Limits of Philosophy (London: Fontana, 1985), p.212, n.7).
} 
present purposes. But, for the sake of concreteness, let's very briefly consider a particular way in which one might develop the "revise" response:

It is permissible to switch from (ii) to (i) only if the agent chooses (i) for an appropriate kind of reason, e.g., in order to avoid the cost of giving. ${ }^{24}$ Choosing (i) merely in order to avoid wrongfully doing (ii), when one could have at no extra cost avoided this wrongdoing by doing (iii) instead, is intuitively an inappropriate kind of reason. So, we get different moral rankings of (i), (ii), and (iii) depending on the agent's reason for choosing (i). It needn't be that all cases of switching from (ii) to (i) involve choosing (i) for an inappropriate kind of reason, but some do, and in these cases it is wrong to choose (i).

Alternatively, one can offer a more nuanced version of the "resist" response, distinguishing between act assessments and agent assessments. For instance, one might argue that, while switching from (ii) to (i) for an inappropriate reason is permissible, the person who acts this way is to some extent morally deficient for having done so for an inappropriate reason. ${ }^{25}$

Again, I need not here settle on whether to resist or revise in response to the above objection. The availability of one response if not the other is good enough for now; future work might take this further, determining which response is most plausible, and more broadly working out what exactly to say about switching from less helpful helping to not helping at all.

\section{Incurring Costs by Giving to Some Charities over Others}

Against the Common Assumption, I've argued that there are at least some cases in which there is optionality about whether to give (help) without optionality about where to give (help). But recall that my main claim is stronger than this, i.e., that there are many cases in which there is optionality about whether to give without optionality about where to give.

Nonetheless, once we have the weaker claim, it seems a relatively easy task, philosophically speaking, to defend the stronger claim. The task now consists in determining the prevalence of cases in which the various conditions present allow for optionality about whether to give without optionality about where to give. This is of course largely an empirical matter, but there remain a few philosophically interesting issues about strengthening Avoid Gratuitous Worseness (weak).

First, given the existence of significant moral options, there are many realistic scenarios in which it's plausible that it is permissible not to give a sum of money to charity, even if giving would be much better than not giving. It's easy to imagine such scenarios by simply imagining that the sum of money in question is large, or that the potential donor is not well off financially.

Next, it is likely that there are subsets of charities within the full set of charities you could give to, such that for each subset (a) it would be equally costly for you to give to each of the charities in the subset (again, working with my broad sense of "cost"), e.g., because all these

\footnotetext{
${ }^{24}$ Rulli (unpublished) has independently developed a similar move in response to what she calls the "easy exemption objection" in her work on conditional obligations.

${ }^{25}$ Somewhat similarly, if a runaway train is headed for five people and the only way to stop it from killing them is by diverting it onto a sidetrack on which someone you dislike is trapped, it may remain permissible to divert the train even if you do so merely in order to kill this person. See Frances Kamm, Intricate Ethics: Rights,

Responsibilities, and Permissible Harm (New York: Oxford University Press, 2007), p.132 and for a reply see S. Matthew Liao, "Intentions and Moral Permissibility: The Case of Acting Permissibly with Bad Intentions," Law and Philosophy 31 (2012): 703-724.
} 
charities are equally near to your heart, because they're all for the same cause (e.g., fighting blindness), and (b) the charities in the subset vary substantially in the amount of good per dollar you would do by giving to them. The fact that very many charities within and across charitable cause types differ dramatically in the amount of good they do per dollar donated is welldocumented, especially in the context of priority-setting in global health. ${ }^{26}$ Though debatable, I here assume that these dramatic differences in the amount of good done per dollar between charities generally translate into dramatic differences in the amount of good per dollar you would do by giving to the most cost-effective charities over others. ${ }^{27}$

Within the subset of charities of which (a) holds (e.g., charities fighting blindness), it is wrong to give to those that do much less good per dollar, even when it's not wrong not to give to any charity at all. It seems to me this is already enough to conclude that there are many cases in which there's optionality about whether to give without optionality about where to give.

But for all I've said so far, as long as you care a little bit more about giving to a blindness-fighting charity than a cancer-fighting charity, it would not be wrong to do the former, even if the cancer-fighting charity did much more good per dollar. This is because Avoid Gratuitous Worseness (weak) is so weak; it very meekly says it's wrong to perform a much worse act when the better act would be no costlier to you to perform. But if you cared just a little bit more about one charity than another, that'd constitute some cost, and so Avoid Gratuitous Worseness (weak) would fail to apply. Discussing a philanthropist who was fonder of dogs than people, McMahan writes, "If the cost to her of giving her wealth away made it supererogatory to give it to any charity, the additional cost to her of giving it to charities that would help people rather than ones that would help dogs seems to exempt her from any duty to give it to the former." 28

This argument would fail to support the view that, in Arm Donor, it is permissible to save the one over the one hundred. This is because in Arm Donor there is no additional cost to you to saving the one hundred rather than the one. But we are now considering cases in which there is some additional cost to you in giving to some charities over others. It is in these cases that McMahan's argument applies.

In response, we could imagine a variant of Arm Donor in which, to save the one you would have to sacrifice your arm, while to save the one hundred you would have to sacrifice your arm and suffer a mild sore throat. It still seems wrong to save the one. While you would not be deliberately refusing to do something much better at no extra cost, you would be deliberately refusing to do something much better at only slightly extra cost. That seems nearly as objectionable, and still wrong. We might make an exception for those who are very badly off,

\footnotetext{
${ }^{26}$ For some relevant facts, see the World Health Organization's Disease Control Priority Project report: http://dcp3.org/dcp2. As I noted, the effective altruism movement (see earlier citations) is largely driven by such facts about dramatic differences in cost-effectiveness.

${ }^{27}$ Strictly speaking, the assumed link here is between the average amount of good done by charities per dollar donated to them and the expected amount of good per dollar your donations would do. For some work that bears on the plausibility of this link, see Garrett Cullity, "Pooled Beneficence," in Imperceptible Harms and Benefits, ed. Michael Almeida (Dordrecht: Kluwer Academic Publishers, 2000), pp.1-23; Shelly Kagan, "Do I Make a Difference?" Philosophy and Public Affairs 39 (2011): 105-141; Julia Nefsky, "Consequentialism and the Problem of Collective Harm: A Reply to Kagan," Philosophy and Public Affairs 39 (2011): 364-395; and Mark Budolfson and Dean Spears, "Effective Altruism, Marginal Impact, and Fundraising: Weak Links in Effective Altruism's Chain" (unpublished).

28 "Doing Good and Doing the Best," manuscript p.6.
} 
or who have in aggregate incurred very large costs for the sake of promoting the good. Perhaps such people are not required to incur any further costs for the sake of promoting the good, no matter how small the costs and no matter much good they would promote if they did incur them. The vast majority of affluent people are not in this exceptional category. Thus, if the dogenthusiast were not in this category, and if it were only slightly costlier to her to give her large sum of money to a much better charity than to give it to the charity for dogs (that does very little good), it would be wrong of her to give in this less good way even though not wrong of her not to give the sum to charity at all.

As I have noted, Avoid Gratuitous Worseness (weak) fails to apply to cases in which there is some extra cost to you in giving to some charities over others. We can thus consider strengthening the principle to various degrees:

Avoid Gratuitous Worseness (still pretty weak): It is wrong to perform an act that is much worse than another, if it is slightly costlier to you to perform the better act, and if all other things are equal.

Avoid Gratuitous Worseness (moderate): It is wrong to perform an act that is much worse than another, if it is moderately costlier to you to perform the better act, and if all other things are equal.

Avoid Gratuitous Worseness (strong): It is wrong to perform an act that is much worse than another, even if it is much costlier to you to perform the better act, and if all other things are equal.

As the Avoid Gratuitous Worseness principle grows in strength, it becomes progressively less intuitively plausible (though like the "weak" variant, the "still pretty weak" variant is still intuitively plausible, full stop). Stronger and stronger variants of the principle will imply there are more and more cases in which it's wrong to give some sum of money to some charities over others, even though not wrong not to donate this sum of money at all.

Moreover, we might distinguish between variants of the principle on the basis of the particular type of cost in question, for example:

Avoid Gratuitous Worseness (moderate / well-being cost): It is wrong to perform an act that is much worse than another, if it is no more than moderately costlier to you in terms of your well-being to perform the better act, and if all other things are equal.

Avoid Gratuitous Worseness (moderate / projects cost): It is wrong to perform an act that is much worse than another, if it is no more than moderately costlier to you in terms of your projects to perform the better act, and if all other things are equal.

The Avoid Gratuitous Worseness principle will likely vary in plausibility depending on the kind of cost in question, e.g., I suspect that Avoid Gratuitous Worseness (moderate / projects cost) is plausible, if the cost is in terms of one's projects only rather than one's well-being, 
whereas as I suspect Avoid Gratuitous Worseness (moderate / well-being cost) is a bit more controversial. One might object that one cannot suffer a loss in terms of one's projects without thereby suffering a loss in terms of one's well-being; the two sorts of loss are inextricably linked. Even if that is correct, we can distinguish between losses to one's well-being that strictly involve losses in terms of one's projects, and losses to one's well-being due to other factors (e.g., incurring pain or losing a limb). And we can accordingly distinguish between different variants of Avoid Gratuitous Worseness. Again, which of these variants of the principle is true will affect the number of cases in which there's optionality about whether to give without optionality about where to give.

We can further alter the strength and applicability of Avoid Gratuitous Worseness by tinkering with its "much worse" variable. For instance, it may still seem wrong to perform an act that is only somewhat worse than another, if it is no costlier to you to perform the better act, and if all other things are equal.

Finally, it is worth noting that in the case of charitable giving (unlike Arm Donor) you are usually able to split your donations among different charities. You're not forced to give all your money to one charity or the other, and considerations of cost to you may permit you to give some portion but not all of your "donation money" to charities closer to your heart over those that do much more good per dollar donated. The remaining portion cannot permissibly be spent on these less good charities.

Assuming there are moral options, it seems a pretty common occurrence for a potential donor to lack optionality with respect to where to give while nonetheless possessing optionality about whether to give.

\section{Summing Up}

It is an interesting and important question what those attracted to moral options, and to nonconsequentialist thinking more broadly, should say about which charities to give to. I've argued that one thing they should say is that there are many cases in which it would be wrong of you to give a sum of money to charities that do less good than other charities you could give to instead, even when it would not be wrong of you not to give the money to charity at all. This claim is consistent with the effective altruist philosophy noted at the outset, and I believe it's a claim nonconsequentialist effective altruists should accept.

Working out with greater precision when one lacks optionality about whether and where to give will require careful assessment of the plausibility of different variants of Avoid Gratuitous Worseness, alongside sober sensitivity to the various morally relevant empirical considerations. I hope such philosophical and empirical investigations will be taken further, to improve the ethics of giving both in theory and in practice. 